\title{
Adenocarcinoma en células en anillo de sello primario de vejiga. Presentación de un caso clínico con tratamiento multidisciplinario
}

\author{
Cruz-Gonzáles GH, Sánchez-Salas RE, Palmer-Román KJ, Sánchez-Rivero FR, Sanchez-Salas R, \\ Daboin I, Mota D, León A. \\ Universidad Central de Venezuela. Hospital Universitario de Caracas. Cátedra de Clínica Urológica. Servicio \\ de Urología. Instituto Anatomopatológico Dr. "José Antonio O’Daly”.
}

Actas Urol Esp. 2007;31(8):919-922

\section{RESUMEN}

\section{ADENOCARCINOMA EN CÉLULAS EN ANILLO DE SELLO PRIMARIO DE VEJIGA. PRESENTACIÓN DE UN CASO CLÍNICO CON TRATAMIENTO MULTIDISCIPLINARIO}

Introducción: El cáncer de vejiga, representa el segundo tumor más común en el tracto genital.

$\mathrm{El}$ adenocarcinoma constituye del 0,5 a $2 \%$ de los tumores vesicales. Desde el punto de vista histológico los adenocarcinomas son mucosecretantes y pueden tener patrones glandulares, coloides o de células en anillo de sello. A pesar de los avances logrados en carcinoma de vejiga, tumores infrecuentes como el adenocarcinoma vesical, no tienen un tratamiento y control estandarizado de la enfermedad.

Método Presentación de un caso clínico de paciente con adenocarcinoma de vejiga, en el cual se realizo tratamiento multidisciplinario oncológico. Revisión de la literatura.

Resultados: Control perioperatorio y seguimiento del paciente, con las respectivas implicaciones que en la terapéutica tienen los resultados de anatomía patológica.

Conclusiones: El adenocarcinoma de vejiga es una entidad patológica poco frecuente. Su tratamiento no se encuentra estandarizado y la intervención multidisciplinaria de estos pacientes constituye la mejor opción terapéutica.

Palabras clave: Cáncer de vejiga. Adenocarcinoma. Tratamiento multidisciplinario. Carcinoma de células en anillo de sello.

\section{ABSTRACT \\ PRIMARY SIGNET RING CELL BLADDER ADENOCARCINOMA. CASE REPORT WITH A MULTIDISCIPLINARY THERAPEUTICAL APPROACH}

Introduction: Bladder carcinoma is the second most frequent genitourinary tumor. Adenocarcinoma accounts for up to 0,5 to $2 \%$ of bladder carcinoma types. The pathology states the bladder adenocarcinomas are mucous secreting lesions with glandular, colloid or signet ring cell patterns. Even the important advances reached in the field of bladder carcinoma, yet less frequent lesions as bladder adenocarcinoma do not have a standarized treatment protocol.

Methods: Case report of a patient with primary signet ring cell bladder adenocarcinoma with a therapeutical multidisciplinary approach. Literature review.

Results: Patient's outcome and follow up, with regard of therapeutical implications based on pathological findings.

Conclusions: Bladder adenocarcionoma is a rare oncological entity. Treatment protocols for these particular tumors are lacking. Multidisciplinary approach represents the best therapeutical intervention.

Keywords: Bladder. Adenocarcinoma. Multidisciplinary approach. Signet ring cell carcinoma. 
$\mathrm{E}$ cáncer de vejiga, representa el segundo tumor más común en el tracto genital. Los factores de riesgo y patogénesis se han descrito en base al carcinoma de células transicionales que representa el 90\% de las lesiones malignas vesicales, sin embargo, existen carcinomas en la vejiga, de células no transicionales, como adenocarcinoma, carcinoma de células escamosas, indiferenciado y mixtos ${ }^{1,2}$.

$\mathrm{El}$ adenocarcinoma constituye del 0,5 a $2 \%$ de los tumores vesicales ${ }^{3}$ Las lesiones primarias a nivel vesical se ven precedidas de cistitis y metaplasia y pueden ser subdivididos en tres categorías de acuerdo a su origen, metaplásico, remanente del uraco o asociado a extrofia ${ }^{4,5}$. Es más común la extensión directa de tumores en órganos adyacentes como colon o próstata.

Desde el punto de vista histológico los adenocarcinomas son mucosecretantes y pueden tener patrones glandulares, coloides o de células en anillo de sello, esta variante es muy poco usual y fue descrita por primera vez en $1955^{4,6,7}$.

Los carcinomas primarios de la vejiga tienden a formarse hacia el piso vesical, mientras que los que se originan en el uraco se desarrollan en el domo vesical. Lo frecuente es que estas lesiones se encuentren localizadas pero con infiltración muscular para el momento del diagnóstico. Se menciona una sobrevida del $40 \%$, a pesar de un manejo quirúrgico agresivo ${ }^{4}$.

\section{CASO CLÍNICO}

Se presenta un caso de masculino de 41 años con clínica de hematuria indolora de 18 meses de evolución, en el que inicialmente se realiza un estudio endoscópico que evidencia la presencia de lesión de aspecto plano, localizada hacia el domo vesical. El paciente es intervenido quirúrgicamente, realizándose resección transuretral de vejiga, en la que se reseca la totalidad del tumor.

El resultado de anatomía patológica de la resección, reporta Adenocarcinoma de vejiga infiltrante, mucusecretante, con células en anillo de sello. Ante tal hallazgo y por la baja incidencia de $\mathrm{ADC}$ a nivel vesical, se proceden a realizar estudios de extensión. Se realizaron endoscopia digestiva superior e inferior, las cuales se verificaron dentro de límites normales. De la misma forma se realiza tomografía abdominopélvica, que evidencia lesión presente hacia el domo vesical, sin demostrar otras lesiones o adenomegalias en la región pélvica.

Por tratarse de una lesión solitaria, infiltrante y localizada hacia el domo vesical, se decidió la realización de una cistectomía parcial, tomando en cuenta la estirpe celular verificada en la lesión, así como la localización en la vejiga, por lo que se procedió a resecar el uraco, desde su inserción umbilical hasta su ingreso en la pared vesical. De la misma forma, se realizó un vaciamiento ganglionar extendido, desde la bifurcación iliaca y hasta la región ilioobturatriz bilateral (Figs. 1, 2, 3, 4, 5 y 6).

\section{HISTOPATOLOGÍA}

Resección transuretral de vejiga

Adenocarcinoma poco diferenciado, mucosecretante, con células en anillo de sello. Extensa infiltración del músculo detrusor. Estudios de inmunohistoquímica no fueron realizados en este caso.

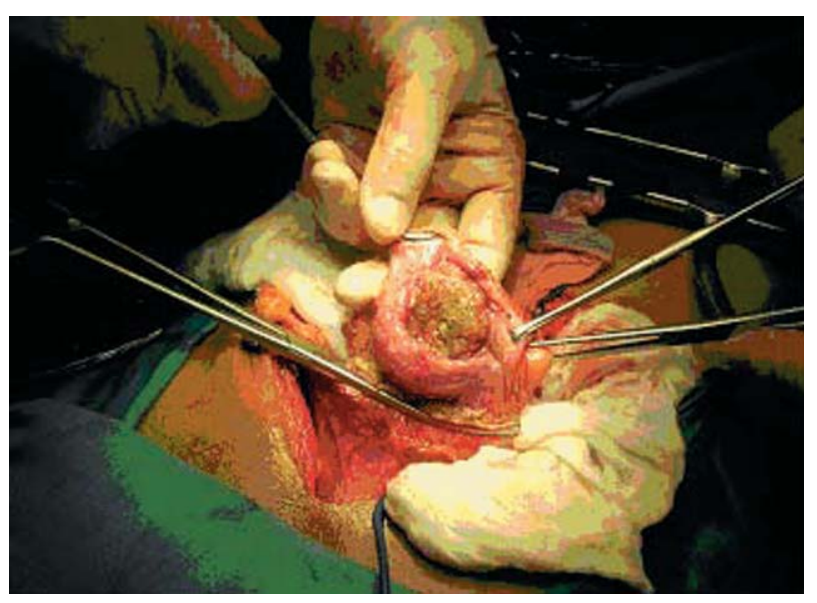

FIGURA 1

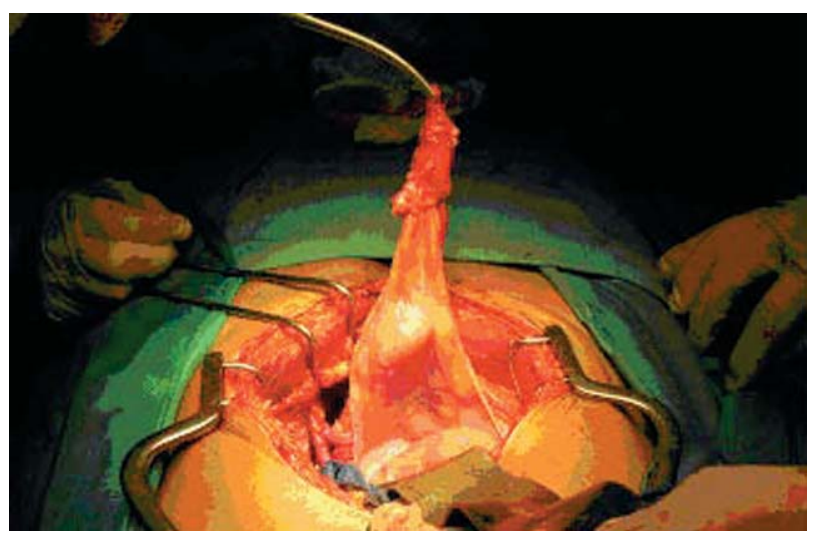

FIGURA 2 


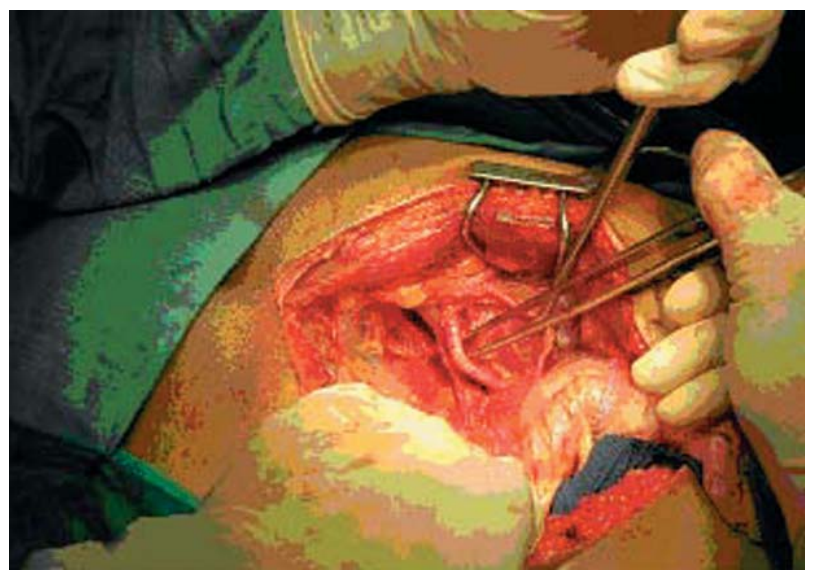

FIGURA 3

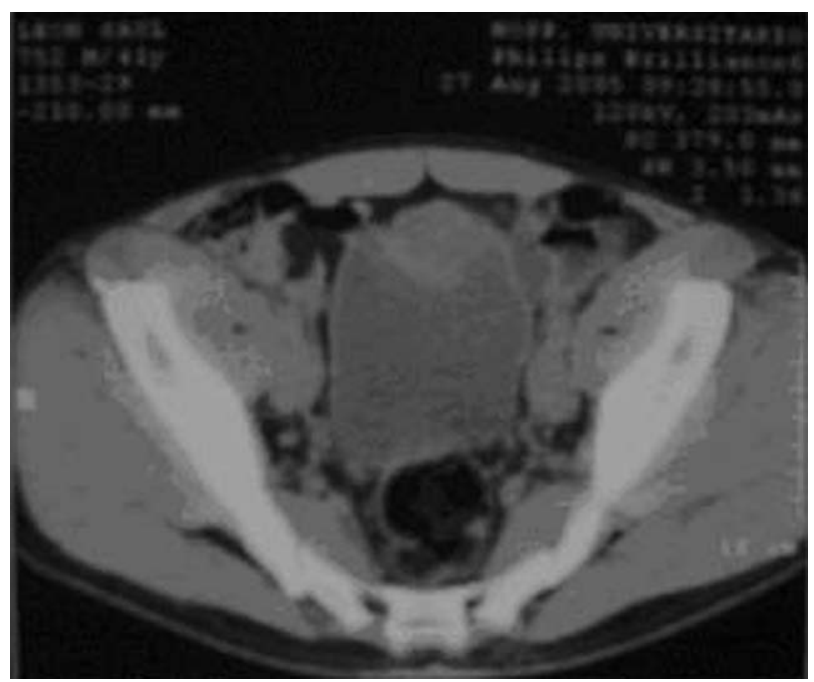

FIGURA 4

\section{Cistectomía parcial}

- Resección de domo y cara anterior. Adenocarcinoma mucinoso con células en anillo de sello. Ulcerado e infiltrante de lámina propia y músculo detrusor hasta la capa externa, sin compromiso de la grasa perivesical. Ganglio perivesical con focos de micrometástasis. Presencia de displasia urotelial en tejido circundante de lesión de origen glandular.

- Focos de neoplasia intraepitelial de alto grado en urotelio adyacente al tumor.

- Uraco. Tejido conjuntivo fibroso, adiposo y vasos libres de tumor.

Ganglios ilio-obturatriz bilateral. Hiperplasia reactiva inespecífica. Sin evidencia de metastásis.

- Bordes de resección libres de tumor.

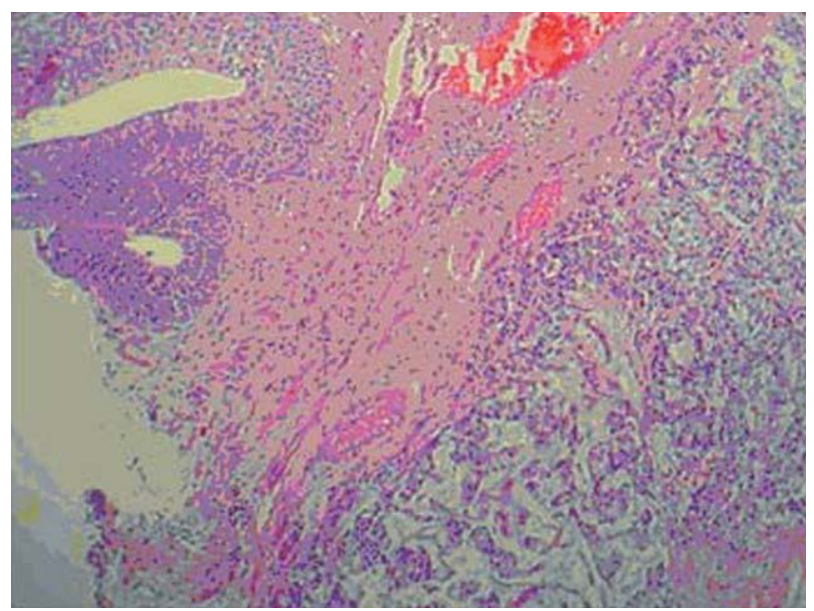

FIGURA 5

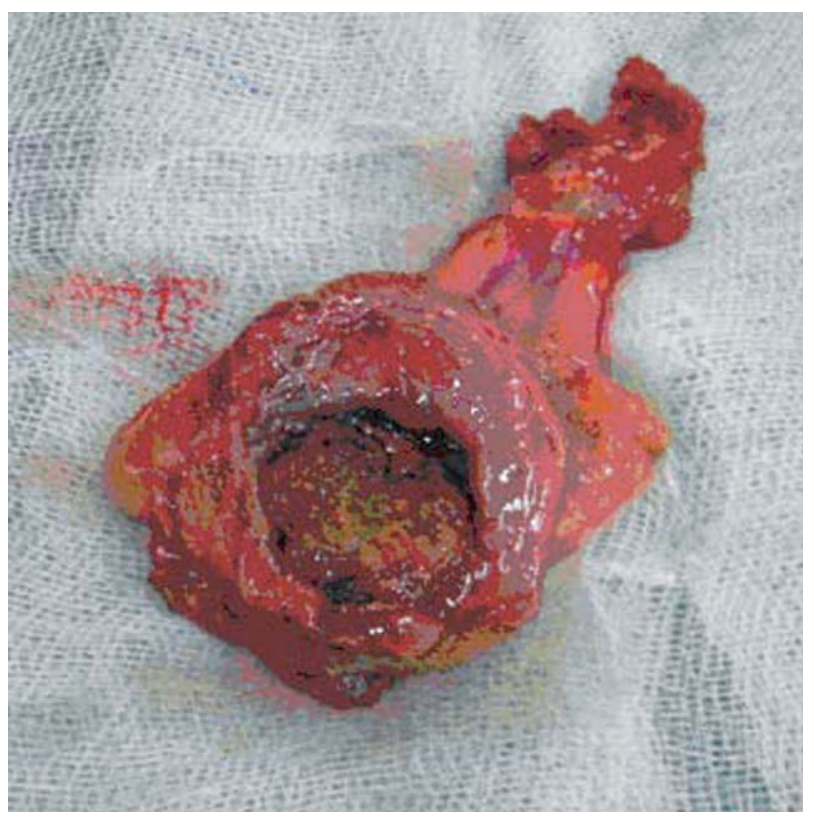

FIGURA 6

\section{DISCUSIŌN}

El adenocarcinoma vesical constituye una rara entidad oncológica, cuya frecuencia es inferior al $2 \%^{8}$.

El conocimiento que se tiene de esta enfermedad se ha obtenido en su mayoría de reportes de casos islados $^{9}$, y son escasas las series como las de Thomas et $\mathrm{al}^{10}$, Torenbeek et $\mathrm{al}^{4} \mathrm{o}$ Grignon et al. ${ }^{11}$, donde se reporta control y evolución de los pacientes.

Se presenta un caso de paciente masculino de 41 años con cuadro de hematuria de larga data con adenocarcinoma primario vesical con células en anillo de sello. 
La literatura reporta una clara frecuencia superior para el sexo masculino ${ }^{4}$, pero el grupo etáreo de nuestro paciente esta por debajo de la séptima u octava década de la vida presentada en los reportes.

Se describen conductas quirúrgicas agresivas para el tratamiento del adenocarcinoma vesical. En el presente caso, por tratarse de una lesión circunscrita localizada en el domo vesical se decidió la realización de una cistectomía parcial, en el marco de un paciente joven con estudios de extensión negativos para lesión tumoral extravesical. El objetivo de la cistectomía parcial es el control de la enfermedad neoplásica mientras se preserva una vejiga funcional, continencia y potencia $^{12}$; es un procedimiento quirúrgico reservado para pacientes muy bien seleccionados, la literatura describe que solo $6 \%$ a $19 \%$ de todos los pacientes con cáncer de vejiga son tratados quirúrgicamente con este procedimiento ${ }^{13}$. Paul et al. ${ }^{5}$ presentaron un caso de adenocarcinoma vesical de origen uracal que fue tratado de manera satisfactoria mediante cistectomía parcial con sin recidiva tumoral en el control postoperatorio.

A pesar de la localización de la lesión en el domo vesical, el estudio histopatológico no evidenció presencia de tumor a nivel de la estructura del uraco, lo que nos podría hacer pensar que se trate de una variante primaria de células en anillo de sello. La presencia de micrometástasis en ganglio perivesical nos habla de enfermedad fuera de la vejiga, por lo que se consideró la posibilidad de tratamiento adyuvante, teniendo como aditivo particular, el hallazgo de focos de neoplasia intraepitelial de alto grado en urotelio adyacente al tumor.

El cáncer de vejiga es una enfermedad que ha mostrado aumento en la incidencia pero disminución en la mortalidad. Diferentes carcinógenos del urotelio han sido identificados, tales como las aminas aromáticas, gases combustibles, componentes dietéticos de la carne y tabaquismo. La patogénesis de la enfermedad se ha dilucidado en las mutaciones del p53 y $\mathrm{Rb}$ así como en los genes del cromosoma $8^{13}$. A pesar de los avances logrados, existen grupos de tumores infrecuentes como el adenocarcinoma vesical, donde los conocimientos desarrollados no permiten un tratamiento y control estandarizado de la enfermedad.
El paciente fue evaluado por oncologia médica, quienes plantearon un tratamiento adyuvante basado en esquema MVAC. A los tres meses postoperatorios, el paciente se encuentra en condiciones estables, programado para seguimiento estricto.

\section{REFERENCIAS}

1. Grossfeld GD, Carrol PR. Urothelial carcinoma: Cancers of the bladder, ureter and renal pelvis. In: Smith's General Urology. 16 $6^{\text {th }}$ edition. Chapter 20, pp 324-345, 2004.

2. Osca García JM, Alfaro Ferreres L, Alonso Gorrea M, Ruiz Cerdá JL, Martínez Jabaloyas J, Jiménez Cruz JF. Adenocarcinoma primario de vejiga. Arch Esp Urol. 1993;46 (2):107-111.

3. Sánchez Zalabardo D, Rodríguez González J, Fernández Montero JM, López Ferrandis J, Arocena García-Tapia J, Sanz Pérez G, et al. Adenocarcinoma vesical primario: nuestra experiencia en los últimos diez años. Actas Urol Esp. 2001;25(8):573-577.

4. Torenbeek R, Koot RA, Blomjous CE, De Bruin PC, Newling DW, Meijer CJ. Primary signet-ring cell carcinoma of the urinary bladder. Histopathology. 1996;28(1):33-40

5. Paul AB, Hunt CR, Harney JM, Jenkins JP, McMahon RF. Stage 0 mucinous adenocarcinoma in situ of the urachus. J Clin Pathol. 1998;51(6):483-484.

6. Ranadive NU, Trivedi VD, Gadgil NM. Primary adenocarcinoma of the urinary bladder: a study of six cases from the pathologist's point of view. Arch Esp Urol. 1999;52(8):906911.

7. Saphir O. Signet-ring cell carcinoma of the urinary bladder. Am J Pathol. 1955;31(2):223-231.

8. Herr HW, Shipley WV, Bajorin DF: Cancer of the Bladder. In: Cancer: principles and practice of oncology. $6^{\text {th }} \mathrm{Ed}$, Section 3, 1396-1418, 2001.

9. Gonzalez E, Fowler MR, Venable DD. Primary signet ring cell adenocarcinoma of the bladder (linitos plastica of the bladder: report of a case and review of the literature. J. Urol. 1982;128(5);1027-1030.

10. Thomas DG, Ward AM, Williams JL. A study 52 cases of adenocarcinoma of the bladder. Brit J Urol. 1971;43(1);415.

11. Grignon DJ, Ro JY, Ayala AG, Johnson DE, Ordóñez NG. Primary adenocarcinoma of the urinary bladder: a clinicopathologic analysis of 72 cases. Cancer. 1991;67(8):21652172 .

12. Holzbeierlein JM, Lopez-Corona E, Bochner BH, Herr HW, Donat SM, Russo P,et al. Partial cystectomy: a contemporary review of the Memorial Sloan-Kettering Cancer Center experience and recommendations for patient selection. J Urol. 2004;172(3): 878-881.

13. Sweeney P, Kursh ED, Resnick MI. Partial cystectomy. Urol Clin North Am. 1992;19(4):701-711.

\footnotetext{
Correspondencia autor: Dr. R. Sánchez-Salas

Universidad Central de Venezuela

Hospital Universitario de Caracas

E-mail autor: sancher1@mskcc.org

Información artículo: Nota clínica

Trabajo recibido: mayo 2006

Trabajo aceptado: septiembre 2006
} 